\title{
PROCESSOS ESTRUTURAIS, SISTEMA PRISIONAL BRASILEIRO E EXECUÇÃO NEGOCIADA DE SENTENÇA JUDICIAL
}

\author{
STRUCTURAL PROCESSES, BRAZILIAN PRISON SYSTEM AND \\ NEGOTIATED ENFORCEMENT OF COURT RULINGS
}

Recebimento em 02/09/2020

Aceito em 24/09/2020

Guilherme Graciliano Araújo Lima ${ }^{1}$

\section{RESUMO}

A realidade dos processos estruturais no Brasil do século XXI trouxe à tona uma nova concepção de como proceder ao cumprimento de decisões que modificam toda a forma de funcionamento e aparelhamento de uma estrutura da Administração Pública, bem como a forma pela qual se deve desenvolver determinada política pública. No presente ensaio, tento esclarecer as formas pelas quais seria possível e viável a conformação da realidade fática com decisões judicias proferidas em processos judicias complexos, cujos contornos exigem do manobrista uma técnica que possa ressignificar postulados comuns do processo judicial e muitos de seus princípios básicos, com destaque para a possibilidade de cumprimento negociado de sentenças condenatórias proferidas contra o Poder Público. Para tanto, utilizarei o método hipotético-dedutivo, com base em pesquisa bibliográfica e documental, com base em julgados sobre o tema e na literatura especializada.

Palavras-chave: 1. Políticas públicas. 2. Processos estruturais. 3. Execução negociada. 4. Sistema prisional brasileiro.

\section{ABSTRACT}

The reality of structural processes in Brazil in the 21st century has brought to light a new conception of how to proceed with the fulfillment of decisions that change the entire way in which a Public Administration structure works and equips it, as well as the way in which a given public policy must be developed. In the present essay, I try to clarify the ways in which it would be possible and viable to conform the factual reality with judicial decisions rendered in complex judicial processes, whose contours demand from the valet a technique that can reframe common postulates of the judicial process and many of its basic principles, with emphasis on the possibility of negotiated compliance with condemnatory sentences handed down against the government. For that, I will use the hypothetical-deductive method, based on bibliographic and documentary research, based on judgments on the subject and in specialized literature.

Keywords: 1. Public policies. 2. Structural processes. 3. Negotiated execution. 4. Brasilian prison system.

${ }^{1}$ Doutorando e mestre em direito pela UFPE. Promotor de Justiça no estado de Pernambuco. 


\section{NOTAS INTRODUTÓRIAS}

O presente trabalho busca associar a ideia de processos e decisões estruturantes e o problema do sistema carcerário no Brasil da atualidade, tentando, como escopo último, demonstrar que a solução para o problema das péssimas condições das unidades prisionais passa, necessariamente, embora não exclusivamente, pelo processo judicial estruturado, com uma fase de execução diferenciada, que auxilia, incentiva e exige dos demais poderes da República, mormente o Poder Executivo, a tomada das medidas cabíveis em termos de políticas públicas voltadas a reduzir as condições degradantes encontradas nos presídios e cadeias do país.

Em um primeiro momento tratarei do processo estrutural, suas principais características e os pontos relevantes do tema, destacados por autores de relevo que estudam com profundidade a matéria, embora essa mesma profundidade não será encontrada neste pequeno ensaio em razão da proposta que aqui me inclino a apresentar, qual seja, um pequeno esboço para compreender a noção de processo coparticipativo, que vai além da mera visão da pretensão resistida e litígio processual como ferramenta útil e indispensável para amenizar os problemas, complexos e multifacetados, que existem no sistema carcerário do Brasil.

$\mathrm{Na}$ segunda parte do ensaio abordarei, resumidamente, aspectos acerca da execução negociada e colaborada de sentença judicial estruturante, que determina a realização de determinada política, tocando no que diz respeito à situação da política de encarceramento prisional, com enfoque na Arguição de Descumprimento de Preceito Fundamental - ADPF - n. 347, em andamento no Supremo Tribunal Federal - STF - na qual, em sede de julgamento de medida cautelar liminar, foi deferida parcialmente a tutela jurisdicional para declarar o Estado de Coisas Inconstitucional - ECI - no sistema penitenciário brasileiro, além de outras medidas emergenciais, tais como a realização de audiências de custódia e o descontingenciamento de verbas do Fundo Penitenciário Nacional.

Ainda nessa passagem buscarei trazer alguns pontos da experiência colombiana acerca do tema do Estado de Coisas Inconstitucional, e como lá medidas judiciais muito semelhantes dos conceitos de decisões estruturantes foram adotadas para amenizar as mazelas sociais daquele país, que, embora não configure na atualidade exemplo do melhor e mais perfeito regime social do mundo, permite-nos analisar as condições, circunstâncias e consequências de medidas e decisões judiciais complexas, especialmente através da figura dos autos de seguimiento, como se verá mais à frente. 


\section{NOÇÕES PRELIMINARES SOBRE PROCESSOS ESTRUTURAIS}

O conceito de decisão estruturante aqui adotado é o desenvolvido pela doutrina jurídica nos Estados Unidos a partir da década de 1960, especificamente no proposto por Owen Fiss e Abram Chayes, ao afirmarem que são estruturantes as decisões judiciais nas quais, a partir de um litígio que transcende o interesse individual e privado e, portanto, é de interesse público, se busca a reestruturação de determinada organização social ou política pública, com o objetivo de concretizar direitos fundamentais ou interesses socialmente relevantes.

A experiência norte-americana e a história nos mostram que o conceito vem desde a Suprema Corte dos Estados Unidos, na época presidida por Earl Warren, com indicações de precedentes como dos anos de 1954 e 1955, especialmente o caso que ficou famoso denominado Brown vs. Board of Education of Topeka, cidade do estado do Kansas, no qual o aludido tribunal constitucional declarou inconstitucional a segregação racial aos estudantes de escola pública. Era o embrião do que se chama na processualística brasileira de processo estruturante.

Especificamente no que diz respeito à relação entre processos estruturantes e sistema carcerário, que é a parte que mais interessa nesse pequeno trabalho, vale salientar que a partir de Holt vs. Sarver, no estado do Arkansas, - caso em que, pela primeira vez, "todo o sistema prisional de um Estado teve sua constitucionalidade impugnada judicialmente" -, a prison law litigation se popularizou nos Estados Unidos e em 1993, quarenta estados norte-americanos enfrentavam ações similares, demonstrando a existência de uma verdadeira rede judicial de litígios estruturais acerca do regime prisional daquele país.

De fato, os desafios do direito processual moderno não permitem mais uma análise meramente legislativa e fria dos institutos de direito processual, especialmente no campo das reformas processuais havidas nas últimas décadas, mas exige, na realidade, um olhar panorâmico de nossa sociedade e uma postura também panorâmica do sistema processual, que abarque as leis processuais, mas também a infraestrutura do Poder Judiciário e seu gerenciamento, mediante a utilização de uma litigância de interesse público, antenada com os problemas sociais que vão além da relação dicotômica processual, dividida entre autor e réu, para viabilizar a obtenção de direitos fundamentais pelos cidadãos como uma maioria mais ampla e diretamente afetada por um provimento jurisdicional.

Nesse sentido, utilizo-me do pensamento do Dierle Nunes e Alexandre Bahia (2010) ao tratarem dos conceitos de policentrismo e comparticipação como mecanismos indispensáveis 


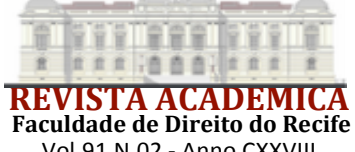

Vol.91 N.02 - Anno CXXVIII

para a formação e construção de um processo resolutivo e mais eficaz, constituindo o autêntico processualismo constitucional democrático, indo além do conhecido caminho de pretensão resistida do autor pelo réu, destacando que o policentrismo evidencia sujeitos muitos outros que, embora possam não figurar como parte processual, irão ser afetados direta ou indiretamente por aquela demanda processual, e a comparticipação, por sua vez, exigindo uma postura ativa, colaborativa e desenvolta das partes durante todas as fases do processo, principalmente na fase da execução e implementação efetiva do provimento jurisdicional.

Para os autores referidos, o processualismo constitucional democrático surge como uma concepção teórica que busca a democratização processual civil mediante a problematização das concepções de liberalismo, socialização e pseudossocialização processual (neoliberalismo processual) e da percepção do necessário resgate do papel constitucional do processo como estrutura de formação das decisões. (NUNES; BAHIA, 2010, p. 83).

Ainda buscando definições e termos para compreender o processo estrutural, é preciso pontuar que os contornos a serem assumidos pelas decisões estruturantes perpassam (i) a competência preferencial para prolação e execução destas decisões; (ii) o fundamento processual da fase de conhecimento e execução; e (iii) a noção ampliada de contraditório e representação que deve orientar este processo. (FACHIN; SHINERMANN, 2018, p. 228.).

Nesse sentido, em relação à competência processual para proferir e executar uma determinada decisão estruturante, a delimitação do tamanho do objeto do litígio poderá acarretar, por exemplo, na competência do STF, quer dizer, essa determinação processual está a depender do grau de resolutividade que se pretende buscar com um provimento jurisdicional estrutural e a depender também da autoridade pública ou pessoa particular a cumprir o provimento.

Isto pode se dar tanto pela impossibilidade de delimitação do pleito - por exemplo, a ADPF 347, em que o pedido referente à realização de audiências de custódia deveria vincular todas as esferas de jurisdição, o que só poderia ocorrer mediante decisão do STF -, como em razão de expressa previsão de competência daquela corte - por exemplo, pleitos que envolvam a disputa entre Estados e que serão submetidos originariamente ao Supremo (art. 102, I, 'f' da Constituição). (FACHIN; SHINERMANN, 2018, p. 230).

Na realidade, embora o exemplo acima referido, o que Melina Fachin e Caio Bueno vão defender é que, via de regra, e de maneira preferencial, as decisões judiciais sobre processos estruturantes devem ser proferidas por órgãos de jurisdição de primeiro grau, dentre outros motivos, por estarem eles mais próximos da realidade local e deterem melhores condições de acompanhar o desdobramento processual após o proferimento de uma decisão de mérito de um processo hipercomplexo e policêntrico. 
Para os referidos autores, ainda que a prolação de decisão se dê no âmbito do STF, a competência para execução da mesma deve ser declinada aos tribunais de segundo grau ou juízos de primeiro grau, a depender de análise do caso concreto. Trata-se de uma ampliação da cadeia decisória no âmbito da tutela executiva que Sérgio Cruz Arenhart denomina "provimentos em cascata”. (ARENHART, 2013, p. 392.).

Assim, nos termos propostos por Owen Fiss, esta ampliação da cadeia decisória implica afirmar que "a execução de uma decisão estruturante tem um começo, talvez um meio, porém não tem fim - ou quase não tem fim”. Esta ampla cadeia decisória pode, muitas vezes, se prolongar significativamente no tempo e é por isso também que Fachin e Shinermann propõem que, mesmo nos casos em que a decisão inicial seja proferida pelo STF, a execução seja declinada aos juízos ordinários competentes.

Vale salientar, nesse ponto, que no direito processual brasileiro, a base normativa para a execução das decisões estruturais, que são necessariamente atípicas, decorre da combinação do art. 139, IV (Art. 139. O juiz dirigirá o processo conforme as disposições deste Código, incumbindo-lhe: IV - determinar todas as medidas indutivas, coercitivas, mandamentais ou subrogatórias necessárias para assegurar o cumprimento de ordem judicial, inclusive nas ações que tenham por objeto prestação pecuniária) com o art. 536, $\S 1^{0^{2}}$, ambos do $\mathrm{CPC}$, pois ambos os dispositivos funcionam como verdadeiras cláusulas gerais executivas, das quais decorre para o órgão julgador o poder de promover a execução de suas próprias decisões através de medidas atípicas, sejam elas coercitivas ou indutivas.

Inobstante os pontos acima tratados, não apenas nas regras de competência e delegação de competência processual para fase de execução ou cumprimento de sentença, e não apenas nos conceitos de policentrismo e de comparticipação é que se limita os escopos e nortes do processo estrutural. É preciso falar também acerca do princípio da congruência.

Com efeito, é típico das medidas estruturais a prolação de uma primeira decisão, que se limitará a fixar em linhas mestras, as diretrizes mais gerais e abrangentes para a proteção do direito a ser tutelado pelo provimento judicial, criando o núcleo da posição jurisdicional sobre o problema a ele levado. Normalmente, após essa primeira decisão - mais abstrata e quase 'principiológica', que define a 'primeira impressão' sobre as necessidades da tutela jurisdicional

Art. 536. No cumprimento de sentença que reconheça a exigibilidade de obrigação de fazer ou de não fazer, o juiz poderá, de ofício ou a requerimento, para a efetivação da tutela específica ou a obtenção de tutela pelo resultado prático equivalente, determinar as medidas necessárias à satisfação do exequente. $\S 1^{\circ}$ Para atender ao disposto no caput, o juiz poderá determinar, entre outras medidas, a imposição de multa, a busca e apreensão, a remoção de pessoas e coisas, o desfazimento de obras e o impedimento de atividade nociva, podendo, caso necessário, requisitar o auxílio de força policial. 
- outras decisões serão proferidas naquela demanda processual judicial para a solução de problemas e questões pontuais, surgidas na fase de execução (cumprimento) da 'decisão-núcleo’, ou para a especificação de alguma prática devida". (DIDIER; ZANETTI JR; OLIVEIRA, 2017, p. 51).

Exatamente por esse fator é que é preciso admitir um grau de atenuação da regra da congruência objetiva externa, que exige uma perfeita sincronia e correlação entre a decisão e a demanda, entre o pedido na inicial e a decisão final de mérito, de modo a permitir ao juiz da causa alguma margem de liberdade na eleição da forma de execução da decisão proferida e de atuação e defesa do direito a ser tutelado. A flexibilidade da congruência objetiva supõe, por isso, que a interpretação do pedido (art. $322, \S 2^{\circ}$, CPC - Art. 322. O pedido deve ser certo. $\S 2^{\circ} \mathrm{A}$ interpretação do pedido considerará o conjunto da postulação e observará o princípio da boa-fé) leve em consideração a complexidade imanente de um litígio processual de natureza estrutural. (DIDIER; ZANETTI JR; OLIVEIRA, 2017, p. 56).

Nesse momento é importante ressaltar o seguinte: decisões proferidas em processos estruturantes não se confundem, necessariamente, com o ativismo judicial, que está muito mais ligado à determinada inclinação técnica e política de determinado julgador sobre casos complexos e que geralmente envolvem políticas públicas ou providências essencialmente a cargo de outros poderes.

O tema do ativismo judicial já foi, e continua sendo, tratado em abundância por diversos autores no país, e não apenas processualistas, mas nesse ensaio é de se observar que as sentenças e decisões proferidas em processos estruturais não tratam especificamente de ativismo judicial, propriamente dito, mas sim de decisões estruturantes que revelam em essência a aplicação do quadro normativo vigente através de medidas concretas, de modo que é plausível concluir que não é o juiz que é ativo, ativas nas políticas públicas no Brasil são as leis e a Constituição Federal. (DIDIER JR.; ZANETI JR, 2017).

Assim, sobre o tema do ativismo judicial, encontramos importante dissenso na doutrina e na jurisprudência brasileira, sobretudo para identificar quais os limites prudenciais de uma postura jurisdicional ativista, e por essa razão "revela-se adequado demonstrar que a atuação do Poder Judiciário ocorre legitimada por uma disfunção política e não por uma atividade política." Trata-se dos limites institucionais estabelecidos naquilo que Didier et al chamam de esfera do "não decidível que” (direitos de liberdade) e do "não-decidível que não" (direitos sociais). Assim, concluem os autores, a "função de garantia, portanto, atua como função contramajoritária, assegurando os limites e vínculos decorrentes do modelo constitucional garantista.” (DIDIER; ZANETTI JR; OLIVEIRA, 2017, p. 58). 
Além das características acima indicadas, Nunes, Cota e Faria apontam que o processo estrutural é dotado ainda de outros pressupostos, tais como causa de pedir e pedido dinâmicos (devido à causalidade complexa); participação potencida (devido à multiplicidade de interesses imbricados); e a geração de decisões prospectivas. (NUNES; COTA; FARIA, 2018, p. 371).

Então temos até o presente momento, e seguindo os pontos abordados por esse ensaio, que afirmar ser o processo estruturante revolto de características próprias que o diferenciam do processo civil comum e ordinário, tais como as seguintes: a delegação de competência processual para fase de execução ou cumprimento de sentença, os conceitos de policentrismo e de comparticipação e a mitigação do princípio (ou regra, como preferem Didier e Zanetti Júnior) da congruência.

É preciso, entretanto, além dos tópicos acima mencionados, ir além no pensamento dos institutos processuais dignos de notas no âmbito dos processos estruturais. Falo aqui do princípio constitucional do contraditório. Vejamos.

Como se pode depreender da leitura dos trechos acima, o processo coletivo, movido geralmente por um órgão ou entidade, tais como Ministério Público, Defensoria Pública entre outros, aliena de participação direta exatamente o grupo que se busca proteger na demanda processual, na medida em que não permite sua participação na relação processual, ao menos na fase de conhecimento, como autor, em decorrência da regra processual da representação, e apenas autoriza a presença, no polo ativo do processo, dos entes legitimados para a tutela dos interesses desses grupos, fazendo tudo isso segundo a mesma lógica da tutela individual, ou seja, segundo um processo bipolarizado, marcado pela atuação de autor contra o réu, onde necessariamente se veem posições antagônicas em que uma deve prevalecer sobre a outra.

Nesse sentido, Sérgio Cruz Arenhart vai aduzir que esse procedimento estrutural exige a satisfação de dois requisitos imprescindíveis. Primeiro, a redefinição da noção de contraditório, de modo que este passe a ser visto como direito de efetivamente influir no convencimento do juiz, onde não pode limitar-se a partes de um conflito abstrato. Além da necessidade de uma revisão conceitual da noção do princípio constitucional-processual do contraditório, os processos estruturais também exigem um procedimento diferenciado, que não se amolda aos parâmetros tradicionais do processo individual.

Elementos esses tais como a adstrição da decisão ao pedido (como referido anteriormente), a limitação do debate aos contornos da causa de pedir, a dimensão da prova, a amplitude do direito ao recurso e os limites da coisa julgada exigem reformulação completa dos alcances de seus sentidos especialmente quando se pensa em processos estruturais. (ARENHART, 2017, p. 73). 
Ademais, além da ênfase nas técnicas de composição consensual e na participação técnica e social, as decisões estruturantes impõem a elaboração de mecanismos de fiscalização e de diálogo na implementação das soluções obtidas, que vão além dos institutos do amicus curiae ou das audiências públicas, mas perpassam outros sujeitos não-processuais, grupos de especialistas, tais como o Grupo de Assessoramento Técnico do Juízo (GTA), formado por representantes técnicos de todas as partes e por sujeitos externos ao processo, ligados à questão ambiental, e responsável por auxiliar na resolução e implementação das decisões judiciais no processo que ficou conhecido como a ACP do Carvão, movida pelo Ministério Público Federal na seção da Justiça Federal de Criciúma, Santa Catarina, e tinha por principais funções propor estratégias, métodos e técnicas para a recuperação ambiental da área degrada pela exploração e extração irregular de carvão.

Além de corpos técnicos, é preciso franquear a participação de cidadãos comuns interessados e diretamente envolvidos na causa discutida pelo Judiciário, inclusive permitindo acesso a movimentos sociais e organizações não-governamentais.

É esse aspecto, exatamente, no tocante à necessidade de uma execução participativa e um cumprimento monitorado da decisão judicial, que mais vai importar quando esse ensaio abordar a questão do sistema carcerário no Brasil e os processos estruturais. Mais à frente me debruçarei com mais afinco nesse ponto, mas, a princípio, é fundamental que o leitor não perca isto de mente: o processo estrutural exige uma implementação da decisão proferida diferenciada, participativa e colaborativa, exigindo a integração de sujeitos que estejam além dos limites da relação processual entre autor e réu, principalmente quando se fala de políticas públicas complexas e permanentes.

Para Arenhart, citando especificamente o caso da ACP do Carvão, a legitimidade das soluções consensuais sobre políticas públicas depende, indubitavelmente, da permeabilidade dessas negociações à participação dos grupos que podem ser atingidos e de especialistas no tema. (ARENHART, 2017, p. 73).

Diante do exposto, percebe-se que os processos estruturais são dotados de uma hipercomplexidade que exigem do juiz e dos sujeitos processuais novas ferramentas instrumentais e novo arcabouço teórico que vá além do já conhecido processo individual. Falouse, como visto, de policentrismo, comparticipação, delegação da competência executória, mitigação do princípio da congruência, causa de pedir e pedido dinâmicos, decisões prospectivas, revisão do princípio do contraditório, e, o que mais interessa aqui, monitoramento judicial e colaboração participativa dos interessados, principalmente do réu condenado, durante a fase do cumprimento da decisão judicial. Sobre isso tratarei a partir de então. 


\section{EXECUÇÃO NEGOCIADA DE DECISÃO JUDICIAL DE POLÍTICA PÚBLICA NO SISTEMA PRISIONAL}

Nessa passagem guiarei os estudos a partir das noções de Eduardo José da Fonseca Costa, juiz federal em São Paulo, tratando acerca da execução negociada de política pública em interessante artigo sobre processos estruturais. (COSTA, 2012).

Como nos ensina Costa, não são poucas as vezes que durante o cumprimento de sentenças condenatórias de implantação de políticas públicas, o roteiro repetitivo se fixa na seguinte situação de que o juiz fixa um prazo intuitivo, o prazo normalmente é extrapolado, o Ministério Publico, por sua vez, protesta, "o juiz fixa multa diária, o réu pede mais prazo, as multas acumulam-se até cifras milionárias e a obrigação de fazer continua sendo descumprida ou cumprida de forma parcial ou insatisfatória”. (COSTA, 2012).

Essa sistemática demonstra, com efeito, que a execução forçada de uma decisão judicial estruturante não é a forma mais eficaz de se implantar em juízo determinada política pública, porquanto ainda se tem que um cumprimento obrigatório e não espontâneo de uma ordem judicial é tido tradicionalmente como sanção e como tal reforça o caráter ilícito de uma conduta anterior, ao qual o gestor público, na grande maioria das vezes, não que ver sua imagem associada.

Para Costa, isso revela, ainda, que muitas vezes não há dolo por parte do agente público responsável pelo cumprimento da decisão exequenda, razão pela qual muitas vezes não se configuram o crime de desobediência definido no artigo 330 do $\mathrm{CP}$, o crime de responsabilidade do prefeito municipal definido no inciso XIV do artigo $1^{\circ}$ do Dec.-lei 201/67 nem o crime de desobediência definido no artigo 26 da Lei 12.016/2009.

O que, em tese, poderia restar configurado é o eventual enquadramento da postura do administrador como ato de improbidade administrativa, mas, segundo o próprio autor supramencionado, já se vê que o enquadramento da conduta do agente público resistente no inciso II do artigo 11 da Lei 8.429/92, como possível ato ímprobo por violação aos princípios da Administração Pública, também não resolve o problema. (COSTA, 2012).

Com isso o autor quer nos dizer que, em verdade, a par de toda carga despótica que possa carregar, a imposição de multa diária, a responsabilização por improbidade administrativa, a intervenção em estado ou município e a responsabilização criminal do agente público não constituem medidas de bom desempenho na implantação judicial de uma política pública, 
sobretudo quando essa política se carrega por um alto grau de complexidade, envolvendo diversos atores e agentes estatais, e um dispêndio volumoso de tempo e de energia.

Aqui posso ressaltar políticas públicas como fornecimento constante de medicamentos de alta complexidade, construção de aterros sanitários em substituição de lixões, e, no que mais interessa ao meu tema, a implementação de reformas, melhorias e construção de novos presídios e estabelecimentos prisionais, além de aplicação de políticas de desencarceramento.

Uma vez fixada a ordem judicial principal em um processo estruturante, normalmente uma obrigação de fazer, não fazer ou de dar coisa certa, suas minúcias e seu cumprimento muitas vezes se protraem no tempo e, com o decorrer dos fatos práticos, novas necessidades e pequenas alterações no cumprimento do julgado começam a ser percebidos.

Certamente a melhor forma de lidar com essas políticas complexas, com esses fatos menores, porém igualmente relevantes para o cumprimento da política pública, bem como para o cumprimento fiel da ordem judicial e seus desdobramentos, é muitas vezes conveniente uma postura colaborativa do administrador que, na maioria das vezes, pode configurar como executado no processo judicial, sendo espaços bastante propícios para esse cumprimento as reuniões ou as audiências com os envolvidos, nos quais o representante do Poder Judiciário esteja presente.

Segundo Costa, a audiência poderá ser frutífera se os dados forem devidamente utilizados para a construção de uma "execução" negociada, participativa, colaborativa, ocasião em que o réu expõe as reais dificuldades no cumprimento da ordem judicial e demonstra sua capacidade real e concreta de implantar a política pública determinada em decisão judicial, sendo somente após essa exposição que o juiz terá melhores subsídios para propor às partes um acordo sobre o cumprimento voluntário da decisão, estipulando, exemplificativamente, um cronograma de cumprimento. (COSTA, 2012).

Vale ressaltar ainda o pensamento de Eduardo Costa ao dizer que o uso da expressão "execução negociada", com aspas, consiste no fato de que, para o autor, não há, exatamente, uma execução judicial em sentido estrito, pois “o Estado-juiz não invade forçadamente a esfera jurídica do demandado [execução direta], nem por meio de ameaças o compele a fazer algo [execução indireta]".

Porém, com efeito, tomando a palavra execução em sentido amplíssimo (ou seja, no sentido de "efetivação"), pode-se afirmar que, em um processo de efetivação negociada de política pública em juízo, "haveria soft judicial execution (escorada na persuasão, na liquidez, na incitação, na flexibilidade, no diálogo e na criatividade), e não hard judicial execution (escorada na força, na solidez, na coerção, na rigidez, na imposição e na subsunção).” (COSTA, 2012). 
Para o autor, o acordo sobre o cronograma de cumprimento voluntário não configura um ato jurídico stricto sensu e, portanto, um ato executivo, pois naquilo que Costa chamou de “execução judicial negociada”, o réu não tem sua esfera jurídica invadida pelo Estado-juiz, nem é pressionado por medidas coercitivas a cumprir voluntariamente a sua obrigação. Em verdade, para Costa, trata-se de negócio processual ou negócio jurídico “executivo”. (COSTA, 2012).

Antes de tecer comentários acerca do cumprimento de decisão judicial de política pública no sistema prisional, faz-se necessário também trazer à discussão uma necessidade de revisitar o próprio conceito de sentença em um processo estruturante, assim como foi necessário rever as visões clássicas de contraditório, processo bilateral, participação e colaboração na fase de cumprimento/execução da sentença judicial, reformular as noções sobre o princípio da adstrição ou congruência, entre outros conceitos que, pela natureza do processo estrutural, precisam de novas roupagens. Com a noção de sentença não me parece ser diferente.

É que, aqui, na discussão de processo estrutural, o conceito de sentença precisar ir além da concepção de ato judicial que ponha fim no processo, com ou sem julgamento de mérito, porque em processo com este nível de exigência e complexidade, cujos novos desdobramentos, não previsíveis ou esperados, sempre estão aptos a surgir, a necessidade de controle e de termos um final ao processo, no sentido de uma conclusão definitiva, deve ser flexibilizada, permitindo que o fim do processo se prolongue no tempo e que a noção de sentença vá muito além das meras hipóteses do art. 485 e 487 do CPC/15, permitindo várias sentenças no mesmo processo, de modo que cada uma se apresente em variados graus de cumprimento à medida que a realidade da implementação da política pública se apresente.

Para encaixar o tema do processo estrutural com as questões do sistema prisional, precisarei voltar um pouco no tempo para abordar a questão da ADPF 347, cuja cautelar foi julgada em 2015 pelo STF.

A ADPF 347 foi ajuizada pelo Partido Socialismo e Liberdade (PSOL), requerendo, com influência da jurisprudência da Corte Constitucional Colombiana, a declaração da existência do Estado de Coisas Inconstitucional do sistema prisional brasileiro, em razão das latentes omissões institucionais dos poderes Executivo e Legislativo, e também do Poder Judiciário, para tratar de solucionar o caos vivido no regime prisional nacional.

Os fundamentos de fato e de direito levantados pelo autor da ação perpassam as seguintes diretrizes: violação massiva e generalizada de direitos humanos; expressivo quantitativo de pessoas vítimas da citada violação; omissão das autoridades públicas no cumprimento de suas obrigações institucionais para garantia e promoção dos direitos das pessoas referidas; necessidade de medidas complexas, a serem executadas por vários órgãos do Poder Público, 
exigindo mudanças estruturais, atingindo, inclusive, a necessidade de alterar as previsões orçamentárias da Administração Pública; e o risco de sobrecarregamento intenso do sistema de justiça nacional acaso haja multiplicidade de requerimentos dos indivíduos que são atingidos por aquela situação para solucionar a questão.

A inicial da ADPF parte do pressuposto de que existe no sistema carcerário nacional um cenário patente de violação a direitos mais básicos dos presos, especialmente no que diz respeito a preceitos fundamentais como a dignidade da pessoa humana, a vedação de tortura e de tratamento desumano, bem como o acesso à Justiça e os direitos sociais primordiais como o acesso a saúde, educação, trabalho e segurança.

Os pedidos cautelares apresentados pelo autor, que foram muito extensos, podem ser resumidos da seguinte maneira: a) determinação a todos os juízes e tribunais que motivem expressamente, em cada processo criminal pelo qual haja um preso, as razões que impossibilitam a aplicação das medidas cautelares do art. 319 do Código de Processo Penal no caso concreto sob sua jurisdição; b) reconhecimento da aplicabilidade imediata dos arts. 9.3 do Pacto dos Direitos Civis e Políticos e 7.5 da Convenção Interamericana de Direitos Humanos, para a realização de audiências de custódia, no prazo máximo de 90 dias, por todo o país; c) aplicação de penas alternativas à prisão em razão das condições desumanas das cadeias e prisões do país em casa processo de réu preso; d) abrandamento, pelo juiz da execução penal, dos requisitos temporais para a fruição de benefícios prisionais e direitos do preso; e) determinação para realização de mutirões carcerários; f) determinação do imediato descontingenciamento das verbas existentes no Fundo Penitenciário Nacional - FUNPEN, e vedação à União de realização de novos contingenciamentos até que se reconheça a superação do Estado de Coisas Inconstitucional.

Por sua vez, apreciando o requerimento de medida cautelar formulado na ação, o STF deferiu parcialmente o pedido do autor para declarar e determinar apenas o seguinte: 1) está configurado o Estado de Coisas Inconstitucional no sistema carcerário do Brasil, em razão das condições desumanas de encarceramento dos presos e da violação massiva e persistente de direitos fundamentais em razão da superlotação do sistema, decorrente de falhas estruturais e da falência de políticas públicas, cuja modificação depende de medidas abrangentes de natureza normativa, administrativa e orçamentária; 2) necessidade de a União providenciar o descontingenciamento das verbas do Fundo Penitenciário Nacional, ante à situação precária das penitenciárias nacionais, providenciando a liberação dos valores existentes no referido fundo; 3) estão obrigados os juízes e tribunais de todo o país, com espeque nos artigos 9.3 do Pacto dos Direitos Civis e Políticos e 7.5 da Convenção Americana de Direitos Humanos, a realizarem, em até noventa dias, audiências de custódia, viabilizando o comparecimento do preso perante a 
autoridade judiciária no prazo máximo de 24 (vinte e quatro) horas, contado do momento da sua prisão. $^{3}$

Na decisão em questão é patente que o STF exerceu sua faceta ativista, determinando a realização de políticas públicas de fundo, direta e nitidamente, orçamentário, o que, como bem se sabe, é função precípua do Poder Executivo, bem como ao determinar, sem previsão legal expressa, a realização de audiências de custódia em todo o território do país, matéria afeta ao processo penal, que, como não é desconhecido, nos termos do art. 22, inciso I, da Constituição Federal, seria função privativa do Congresso Nacional.

Uma vez estipuladas diretrizes gerais acerca da ADPF 347, é preciso ter em mente que o cumprimento de decisões judiciais que determinem providências do Poder Público para melhorar as condições do encarceramento no país se dará no âmbito de processos estruturais, de efetivação de políticas públicas, e seguirão a diretriz do STF ao reconhecer que o sistema carcerário no país viola de maneira constante direitos fundamentais das pessoas presas. Trata-se, desse modo, de uma situação hipercomplexa cuja resolução demanda postura ativa e colaborativa do Poder Público competente, especialmente da Administração Pública.

Não pairam dúvidas acerca da natureza estruturante da decisão judicial emanada nos autos da ADPF 347 e do caráter estruturante da própria ação em si, pois um dos pedidos finais da petição inicial é que o Estado, através do Poder Executivo federal e estaduais, apresente um plano de ação para o sistema carcerário brasileiro, visando a reduzir as transgressões de direitos, o que implica, em outras palavras, a execução de uma determinada política pública conduzida por um órgão judicial.

Críticas diversas sobre essa postura certamente surgiram e outras ainda surgirão. Posso destacar algumas, entre elas aquela que diz que essa forma de decisão judicial constitui um excesso de ativismo do Poder Judiciário sobre o Poder Executivo, mas para essa afirmação vale repetir o que é dito por Fredie Didier e outros, ao afirmarem que as sentenças e decisões proferidas em processos estruturais não tratam especificamente de ativismo judicial, propriamente dito, mas sim de decisões estruturantes que revelam em essência a aplicação do quadro normativo vigente através de medidas concretas, de modo que é plausível concluir, como fazem os citados autores, que não é o juiz que é ativo, ativas nas políticas públicas no Brasil são as leis e a Constituição Federal.

3 BRASIL. Supremo Tribunal Federal. ADPF 347 MC, Relator(a): Min. Marco Aurélio, Tribunal Pleno, julgado em 09/09/2015. Diário de Justiça Eletrônico, 031, divulgado em 18-02-2016, publicado em 19-02-2016. Disponível em: http://stf.jus.br/portal/jurisprudencia/visualizarEmenta.asp?s1=000302725\&base=baseAcordaos . Acesso em: 02 ago. 2018. 
Há também vozes que se insurgem contra essa determinação de política prisional pelo STF, sob o argumento de que essa postura iria tornar inviável a prática cotidiana das demais atividades jurisdicionais do STF, posto que a corte não teria condições de acompanhar todos os melhoramentos, reformas e necessidades apresentadas por cada um dos 27 estados da federação e também a União, em suas respectivas unidades prisionais.

Além disso, também exsurgem as críticas que aduzem que ao admitir essa postura ativista pela Corte Constitucional estaremos correndo o risco efetivo de o STF substituir o administrador na execução de todas as políticas públicas relevantes e de interesse de uma grande parcela da população do país, sem falar no risco de que processos como esse não terem um fim, posto que sempre haverá o que ser feito a mais e o que melhorar no sistema prisional brasileiro, sobrecarregando ainda mais as atividades do tribunal.

Embora não seja a única maneira para solução do problema, que certamente não apresenta uma única e exclusiva solução, o cumprimento negociado de decisões judiciais estruturais nessa matéria parecer ser a postura mais consentânea com um processo moderno, eficaz e resolutivo. Entendo que será necessária uma implementação mais duradoura e contínua da fase de cumprimento/execução de sentença dessa natureza, coisa que a Corte Constitucional da Colômbia implementou através dos autos de seguimiento, uma espécie de autos de execução de sentença que aqui traduzirei como "autos de acompanhamento".

Naquele país a sentença T-025 de 2004, proferida pela Corte Constitucional da Colômbia é talvez a mais relevante na matéria de cumprimento de políticas públicas e reconhecimento de um Estado de Coisas Inconstitucional, pois diz respeito à situação alarmante de várias pessoas que foram deslocadas ou expulsas de suas regiões de origem, configurando um movimento que ficou conhecido como desplazamiento, no qual pessoas eram retiradas de suas moradias em razão da violência local. Após o relativo insucesso inicial no cumprimento estrito da decisão citada, a corte constitucional passou a exercer o acompanhamento da execução da sentença através dos autos de seguimiento.

Esse tipo processual tem fundamento no artigo 27 do decreto 2591 de 1991 colombiano, ao estabelecer que "el juez (...) mantendrá la competencia hasta que esté completamente restablecido el derecho o eliminadas las causas de la amenaza”, funcionando como dispositivo legal para que a corte colombiana criasse uma sala especial de acompanhamento da sentença T 025/2004, mantendo sua competência para verificar a adoção das medidas concretas e adequadas para assegurar o gozo efetivo dos direitos fundamentais da população deslocada, sendo que nesses autos de acompanhamento o judiciário colombiano, representado pela sua maior corte, requisitou diversos relatórios pormenorizados das autoridades públicas responsáveis pelo 
cumprimento das medidas impostas na sentença mencionada, de modo a exercer um acompanhamento mais próximo das posturadas adotadas pelo Poder Público e os resultados que delas se esperavam.

Como exemplo, posso citar o auto de acompanhamento n. 219/2011, onde a corte realizou uma análise geral do nível de cumprimento da sentença T 025/2004, no que diz respeito ao nível de atenção à população deslocada e determinou que o Governo Nacional deveria proceder, entre outras providências, para corrigir as lacunas protuberantes em (i) política pública de prevenção do deslocamento e (ii) política pública de garantia dos direitos à verdade, justiça, reparação e não repetição, (iii) adoção de um mecanismo de participação ampla e democrática para organizações da população deslocada e (iv) progresso adequado na garantia dos direitos à saúde e educação da população deslocada.

Pois bem. Penso que a adoção de uma execução negociada das sentenças estruturantes relativas ao sistema prisional brasileiro, e me refiro não apenas as decisões da ADPF 347, mas também a todas as outras sentenças proferidas em processos ordinários em primeiro grau, especialmente ações civis públicas, configura um caminho adequado para a solução de problemas tão arraigados e complexos como são aqueles existentes no nosso sistema prisional atual.

Além disso, essa execução negociada precisa vir atrelada de um acompanhamento judicial mais próximos e rotineiro, como fez a Corte Constitucional da Colômbia através dos autos de seguimiento para cumprimento da sentença T-025/2004, seja através de audiências judiciais, reuniões administrativas ou relatórios de execução, com participação efetiva dos atores envolvidos no cumprimento da decisão, com a participação indispensável do juiz da causa, configurando um dos caminhos facilitadores do processo de melhorias das condições das prisões e unidades carcerárias do país, e que minorariam os problemas causados pelo superencarceramento.

\section{CONCLUSÕES}

No presente ensaio, procurei abordar as noções de processos e decisões estruturantes relacionando-as ao problema do sistema carcerário no Brasil da atualidade, buscando apontar que a solução para o problema das más condições estruturais e humanas das unidades prisionais do país perpassa pelo filtro do processo judicial estruturado, através de uma fase de cumprimento diferenciada, que auxilia, incentiva e exige dos atores responsáveis por administrar o sistema prisional a tomada das providências necessárias para a consecução das políticas públicas voltadas 
para reduzir as condições degradantes encontradas nos presídios e cadeias do Brasil, e uma postura colaborativa, e não meramente resistente e litigante.

No que diz respeito ao processo estrutural, suas principais características e pontos relevantes do tema, vimos que conceitos tais como policentrismo, comparticipação, delegação da competência executória, mitigação do princípio da congruência, causa de pedir e pedido dinâmicos, decisões prospectivas, revisão do princípio do contraditório, e monitoramento judicial e colaboração participativa dos interessados, inclusive do réu condenado, na fase do cumprimento da decisão judicial, trazem uma nova roupagem ao processo civil estrutural que vai bem além e diferencia-se bastante das regras e princípios do processo civil clássico, constituído basicamente de uma relação bilateral, entre autor e réu.

Nesse sentido, dei ênfase aos aspectos acerca da execução negociada e colaborada de sentença judicial estruturante, que determina a realização de determinada política pública, tocando no que diz respeito à situação da política de encarceramento prisional, com enfoque na ADPF n. 347, em andamento no STF, buscando trazer pontos da experiência colombiana acerca do tema do Estado de Coisas Inconstitucional e como lá no país vizinho medidas judiciais muito semelhantes aos conceitos de decisões estruturantes foram adotadas para amenizar as mazelas sociais levadas ao conhecimento do Poder Judiciário em autos de processos judiciais, através de menções às condições, circunstâncias e consequências de medidas e decisões judiciais complexas, especialmente através da figura dos autos de seguimiento.

Em suma, concluo que a adoção de uma execução negociada das sentenças estruturantes relativas ao sistema prisional brasileiro, em todos os níveis e graus de jurisdição, acoplada a um acompanhamento judicial mais próximo e rotineiro, como fez a Corte Constitucional da Colômbia através dos autos de seguimiento para cumprimento da sentença T-025/2004, com participação efetiva dos atores envolvidos no cumprimento da decisão, especialmente de agentes da Administração Pública executada, com a participação do juiz da causa, pode configurar um caminho facilitador do processo de melhorias das condições das prisões e unidades carcerárias do país, e refletir para amenizar as agruras do encarceramento em massa pelo qual passa o sistema prisional da atualidade.

\section{REFERÊNCIAS}

ARENHART, Sérgio Cruz. Decisões estruturais no direito processual civil brasileiro. Revista de Processo, v. 225, 2013.

ARENHART, Sérgio Cruz. Processos estruturais no Direito brasileiro: reflexões a partir do caso da ACP do carvão. Revista do TRF 1, Brasília v. 29, n. 1/2 jan./fev. 2017. 
COSTA, Eduardo José da Fonseca. A 'execução negociada' de políticas públicas em juízo. Revista de Processo, v. 37, n. 212, p. 25-56, out., 2012. Disponível em: https://www.lexml.gov.br/urn/urn:lex:br:rede.virtual.bibliotecas:artigo.revista:2012;1000952463. Acesso em: 30 dez. 2019.

DIDIER JR., Fredie; ZANETI JR., Hermes. Curso de Direito Processual Civil. Processo Coletivo. 11. ed. Salvador: Editora Juspodivm, 2017.

DIDIER JR., Fredie; ZANETI JR., Hermes; OLIVEIRA, Rafael. Notas sobre as decisões estruturantes. Civil Procedure Review, v. 8, n.1, p. 46-64, jan./abr. 2017.

FACHIN, Melina Girardi; SHINERMANN, Caio Cesar Bueno. Decisões estruturantes na jurisdição constitucional brasileira: critérios processuais da tutela jurisdicional de direitos prestacionais. Revista Estudos Institucionais, v. 4, n. 1, 2018.

NUNES, Dierle; BAHIA, Alexandre. Processo, jurisdição e processualismo constitucional democrático na América Latina: alguns apontamentos. Revista Brasileira de Estudos Políticos, Belo Horizonte, n. 101, p. 61-96, jul./dez. 2010.

NUNES, Leonardo Silva; COTA, Samuel Paiva; FARIA, Ana Maria Damasceno de Carvalho. Dos litígios aos processos estruturais: pressupostos e fundamentos. In: FARIA, Juliana Cordeiro de; REZENDE, Ester Camila Gomes Norato; NETO, Edgard Audomar Marx.(org.). Novas tendências, diálogos entre direito material e processo: estudos em homenagem ao professor Humberto Theodoro Júnior. Belo Horizonte: Editora D’Plácido, 2018. 